NOTICE: this is the author's version of a work that was accepted for publication in the journal Research in International Business and Finance. Changes resulting from the publishing process, such as peer review, editing, corrections, structural formatting, and other quality control mechanisms may not be reflected in this document. Changes may have been made to this work since it was submitted for publication. A definitive version was subsequently published in the journal Research in International Business and Finance, Vol.33, (2015). DOI: 10.1016/j.ribaf.2014.06.002 


\section{Better the Devil You Know: The influence of political incumbency on Australian financial market uncertainty}

The Australian federal election cycle, which occurs approximately every 3 years, causes much media attention and invokes indecision regarding investment decisions in both the real economy and financial markets. This paper constructs measures of political uncertainty and formally explores their relationship with market uncertainty, as measured by implied volatility. The empirical evidence suggests that increasing (decreasing) levels of uncertainty around the election result induce higher (lower) levels of market uncertainty. In a case of the market preferring the devil it knows, an increasing (decreasing) likelihood of the incumbent party, whose economic policies are well-known, winning the election, reduces market uncertainty. The results remain significant even after controlling for a number of macroeconomic variables.

Key-words: Political Uncertainty, Investor Sentiment, Financial Market Uncertainty, Implied Volatility, Exchange Traded Options, Stock Markets JEL Classification Codes: C22, C23, G1, G10, G15, G18, H3 
'Nothing is but what is not' - William Shakespeare (1605)

\section{Introduction}

The September 2013 federal elections in Australia brought to an end months of media commentary and speculation as to the likely winner, and the prospective future direction of fiscal and economic policy should a particular party win. Existing literature indicates that such political factors influence both the returns and risk levels of financial assets. Hibbs (1986) suggests that economic policies are conditioned by political forces, and party differences in policy have the potential to move the economy along different time paths and manifest in different returns to both stock- and bond-holders. Julio and Yook (2012) provide evidence connecting political uncertainty to changes in fundamentals of the real economy as firms reduce expenditures during times of political uncertainty.

Prior studies have found substantial evidence for the influence of political outcomes on the stock market with the substantive finding that market uncertainty tends to rise as the election approaches and uncertainty about the result increases. Li and Born (2006) find that whilst the mean daily stock return rises in the 3-month period prior to U.S. elections when the outcome is uncertain, it is indistinguishable from the non-election period when the incumbent party is assured of re-election. Goodell and Vähämaa (2013) utilize data from the Iowa Electronic Market, a betting market for the U.S. Presidential election, and find support for the political uncertainty hypothesis which presumes that information regarding the probability of a particular election winner reflects information about future macroeconomic policy.

Three studies have attempted to form an international perspective on the political uncertainty-market uncertainty relationship: Gemmill (1992) discovers a close relationship between U.K. polling and the FTSE Stock Index, with some evidence of ill-informed option speculators creating a bubble in the week prior to the election. Pantzalis et al. (2000) report that the connection between political uncertainty and the stock market differs in countries of varying political, economic and press freedom. Bialkowski et al. (2008) investigate a sample of 27 OECD countries and find that investors are often surprised by the election outcome with stock market return variance doubling during the week around the election. Importantly, the margin of victory and changes in political orientation of government are key factors in explaining the magnitude of the election shock. 
In terms of the impact that elections have on the macro-economy of a nation, this study fits within the more general field of research into the impact of news announcements and their effect on market uncertainty and implied volatility. The general result is that an upcoming scheduled news event induces an increase in market uncertainty that quickly dissipates once the announcement is made. Nikkinen and Sahlström (2004), Ederington and Lee (1996) and Smales (2013) report a rise in the volatility of financial asset prices as an approaching macroeconomic announcement creates uncertainty and then falls quickly when the data is released.

Vähämaa, Watzka and Äijö (2005) investigate how option-implied return distributions change in bond futures in-light of macroeconomic news announcements, and report that expected volatility increases in response to higher than expected inflation and unemployment announcements. Nikkinen and Sahlström (2004), Chen and Clements (2007) and Vähämaa and Äijö (2011) examine the behaviour of implied volatility around FOMC monetary policy decisions and document that, having risen prior, implied volatility falls following the decision as uncertainty is resolved. Donders and Vorst (1996) utilize a similar methodology to examine the implied volatility behaviour of call options around scheduled firm-specific news announcements and report a substantial increase in implied volatility in the pre-event period and a sharp drop after the news release. To-date, there has been little empirical work concerning implied volatility indices in the Australian context. However, Frijns et al. (2010) construct an implied volatility index for the Australian equity market and observe a significant and asymmetric relationship between the volatility index and stock returns; echoing prior findings in U.S. markets.

French and Porteba (1991) note that investors have a significant home bias and predominantly hold domestic assets, thus they will have a significant amount of country-specific political risk within their portfolios. For such risk-averse investors it is essential to gain a full and proper understanding of the relationship between political uncertainty and market uncertainty. This paper asks a single key question: does political uncertainty impact market uncertainty? Relating this question to prior research, two hypotheses are formulated.

$\mathrm{H}_{1}$ : Consistent with Goodell and Vähämaa (2013), an increase (decrease) in political uncertainty will lead to an increase (decrease) in market uncertainty as measured by implied volatility - i.e. there is a positive relationship. 
$\mathrm{H}_{2}$ : In-line with extant literature suggesting that financial market uncertainty ensues from macroeconomic uncertainty; familiarity with the economic policies of the incumbent party, particularly one that is business friendly, will result in market uncertainty falling (rising) as the likelihood of the incumbent party winning the election increases (decreases) - i.e. there is a negative relationship.

Whilst the empirical framework is essentially taken from Goodell and Vähämaa (2013) this paper still succeeds in making several contributions to the existing literature. Firstly, in contrast to Goodell and Vähämaa (2013) who assume the outcome of the election is known a priori, I use polling data to construct unique measures of ex-ante political uncertainty. Secondly, prior work has focused heavily on equity markets and ignored bond markets yet it is likely that a change in government would also have an impact on bond yields, particularly through fiscal policy, and therefore this study attempts to rectify that prior omission. Finally, by extending the existing work to an Australian dataset the results are placed in the context of an electoral system that has very different characteristics in so far as there exists variable timing ${ }^{1}$ of federal elections and where voting is also compulsory.

The empirical findings establish a clear relationship between Australian financial market uncertainty, as measured by implied volatility, and political uncertainty around federal election polling. In particular, the implied volatility of both equity and bond options increases in line with election uncertainty around the outcome of the poll result. The likelihood of the incumbent remaining in power reduces market uncertainty; consistent with the market preferring incumbents where economic policy is known, i.e. preferring the devil it knows, and a particular preference for parties which are viewed as more sympathetic towards business. The results are significant even after controlling for macroeconomic variables and the possibility that economic conditions may affect voting intentions.

The remainder of this paper proceeds as follows. The second section provides background information on the nature of Australian federal elections and also describes the election, financial and macroeconomic data used in the empirical analysis. The third section presents methodology and reports the empirical findings on the role of political uncertainty in the uncertainty of equity

\footnotetext{
${ }^{1}$ The election can be held a maximum of 3-years after the Parliament sits following the prior election.
} 
and bond markets. Finally, section four provides concluding remarks and suggestions for future research.

\section{Data}

\subsection{Election Uncertainty in Australian Federal Polls}

The Australian Parliament was established in 1901 and voting is compulsory, with the use of transferable proportional voting to elect the Senate (the upper house). However, it is the federal elections for the House of Representatives (the lower house) that are of most interest during this study as outcome forms the basis for Government; a full-preference instant runoff voting system is used in which voters number the candidates on the ballot paper in the order of their preference ${ }^{2}$. House elections take place at least every 3 years, with the 2010 election resulting in the first hung parliament since 1940, and the most recent election (September 2013) witnessing a change in government.

Whilst the Australian political system consists of many political parties, only two have a realistic chance of winning representation in the House and forming a government. As such, there is a de facto two-party system with the Australian Labor Party (ALP) the socialist (left) end of the political spectrum and the Liberal-National Party (L-NP) Coalition ${ }^{3}$ espousing more conservative (right) views. Traditionally, the ALP has had a predilection for fiscally expansionary policy that favours workers and unions, while the L-NP has in general favoured smaller government and policy that favours business. At the most basic level the differences between Australian political parties are analogous in many ways to that between the Democratic (Labour) Party and the Republican (Conservative) Party in the U.S. (U.K.).

In the eight federal elections held in Australia since 1993, the stock market has risen by an average of $2.2 \%$ in the month prior to a L-NP election win, and fallen by $0.9 \%$ in the month prior to an ALP win. In the month subsequent to the election result, the stock market has rallied by $2.2 \%$ on average regardless of the winner. Once election uncertainty is resolved on polling day, volatility measures fall by $24.9 \%$ (13.7\%) following L-NP (ALP) success. This suggests that the stock market rises (falls) in anticipation of business friendly (unfriendly) policies by the L-NP (ALP) and then continues to rise as uncertainty about the election and subsequent policies is

\footnotetext{
${ }^{2}$ See www.aec.gov.au for more detailed information.

${ }^{3}$ Officially, the Coalition consists of the Liberal Party of Australia, the National Party of Australia, the Liberal National Party and the Country Liberal Party.
} 
resolved. The reaction to electoral results is somewhat different in the bond markets. Yields on 5year government bonds rise by 3.7\% (9.3\%) on average following L-NP (ALP) poll wins, and the change in yields in more pronounced when comparing to changes in U.S. yields over the same time period; Australian yields rise by 10\% (1.2\%) more than comparative U.S. yields in the month prior to an ALP (L-NP) win and while yields continue to rise relative to those in the U.S. in the aftermath of an ALP win, they actually fall (by $4.0 \%$ on a relative basis) following a L-NP win. Likely, this result owes much to the market reflecting differences in economic policy inherent within the two parties, and in particular the expansionary fiscal policy generally pursued by the ALP.

The two-party preferred vote (2PP) is the result of an election or opinion poll after preferences have been distributed to the two major parties. Owing to the nature of the Australian electoral system, the two-party preferred vote data collected by polling companies is of particular interest when seeking to determine the likely winner of forthcoming elections. This study utilizes federal voting intention data expressed as a two-party preferred vote provided by Roy Morgan Research; a leading independent polling company ${ }^{4}$. Figure 1 - Panel A depicts how the ALP and L-NP have performed in the opinion polls for the four Federal elections in the 2000 - 2013 timeframe on the basis of $2 \mathrm{PP}$ polling.

In this study, the release of the poll is defined as the date on which it could begin to influence financial market returns. For example, if a poll is released on a Sunday then the next trading day is taken to be the poll date. For each election year, I examine polls for the calendar year prior to polling day; since polls are generally released on a fortnightly basis this will give a base sample of 26 fortnightly releases of polling data, to which is added additional weekly polls that take place in the period immediately prior to the election data ${ }^{5} . I U_{n, t}$, a measure of Australian federal election uncertainty is constructed, where $n$ refers to the election year and $t$ refers to the time until the election date. The 2PP opinion poll result for the party out of power, $O_{n, t}$, is subtracted from the 2PP result for the party of the incumbent Prime Minister, $I_{n, t .}$. The difference is then divided by the poll's sampling error $\left(\sigma_{n, t}\right)$ :

\footnotetext{
${ }^{4}$ Roy Morgan Research was founded in 1941 and as well as being the longest established public opinion polling company in Australia, is independent from ownership by any media companies, and it's opinion polls were most accurate in forecasting the outcome of the Australian federal elections during the timeframe considered in this study.

${ }^{5}$ To ensure consistency of the polling data I exclude telephone-based polls from the sample owing to their well-documented selection bias.
} 


$$
I U_{n, t}=\left(I_{n, t}-O_{n, t}\right) / \sigma_{n, t}
$$

Following Goodell and Vähämaa (2013), $E U_{n, t}$ is introduced as a second measure of election uncertainty. $E U_{n, t}$ captures the difference between the probability of re-election of the incumbent party, and the probability of the other party winning the election. $E U_{n, t}$ is defined:

$$
E U_{n_{2}, t}=1-\left|P I_{n_{2}, t}-\left(1-P I_{n_{s},}\right)\right|
$$

Where $P I_{n, t}$ denotes the probability of success of the incumbent party. When both parties have an equal probability to become elected (i.e. $P I_{n, t}=0.5$ ) then $E U_{n, t}$ equals one. When either of the parties is certain to win the election (i.e. $P I_{n, t}=0$ or 1 ) then $E U_{n, t}$ equals zero. The test variables utilised within the empirical analysis are $\% \Delta I U_{n, t}$ and $\% \Delta E U_{n, t}$ - the percentage change in the respective measures of electoral uncertainty.

\subsection{Financial Instruments and Macroeconomic Data}

The financial instruments utilized within the empirical analysis are exchange-traded futures and options contracts based on the S\&P/ASX 200 (the leading benchmark for Australia's equity markets) and the 3-year Treasury Bond (the most actively traded Australian bond futures contract). Daily closing data is collected from Thomson Reuters Tick History (TRTH), provided by SIRCA ${ }^{6}$, and the Australian Securities Exchange ${ }^{7}$. To ensure that the study concentrates on the most liquid contracts only the nearest futures contracts are considered. In-line with market convention, the contract under consideration is rolled on the last day of the month preceding the delivery month.

A measure of implied volatility is constructed using the daily closing levels of ATM call and put options; the closing implied volatility level of the two nearest to expiry option contracts are interpolated in order to ensure a constant option maturity of 30 days. This produces a measure, $\sigma_{n, t}^{S P X}$, that represents the expected volatility of the S\&P/ASX 200 (SPX) over the next 30-days, and is similar in fashion to the widely used CBOE VIX index. Similarly, $\sigma_{n, t}^{3 Y B}$ represents the expected volatility of 3-yr Treasury bond futures over the same period. Figure 1 - Panel B depicts how each measure moves over time in the period around the four elections considered in

\footnotetext{
${ }^{6}$ Securities Industry Research Centre of Asia-Pacific

${ }^{7}$ www.asx.com.au

${ }^{8}$ Note that since the implied volatility measure is general much lower for bonds than for equity markets, the measures are re-scaled in order to provide clarity of the evolution of each measure over time.
} 
this article. Note the spike in equity market volatility around the events of September 2001, and the apparent positive relationship between volatility and the 2PP for the ALP.

\section{$<$ Insert Figure 1>}

Since option implied volatility incorporates all available information that is relevant for forming expectations about future volatility, implied volatility is widely considered as the best estimate of market uncertainty. In this study, the variables of interest are $\% \Delta \sigma_{n, t}^{S P X}$ and $\% \Delta \sigma_{n, t}^{3 Y B}$, the percentage change in the implied volatility level of the S\&P/ASX 200 Index options and 3year Treasury Bond options respectively.

Changes in economic optimism and changes in expectations regarding macroeconomic risk will likely impact voting preferences, financial asset prices and market sentiment; therefore, a number of macroeconomic variables are included as control variables. \% $\triangle I N F L$ is the percentage change in inflation as reported by the Australian Bureau of Statistics (ABS). Periods of increasing inflation are typically associated with increases in economic activity and more restrictive changes in monetary policy. \% $\triangle U N E M P$ is the monthly percentage change in unemployment reported by the ABS. $\% \triangle A S X$ is the percentage change in the S\&P/ASX200 Index. \% CONSCONF is the monthly percentage change in consumer confidence as reported by Westpac / Melbourne Institute, and it would be expected that rising consumer confidence would follow from rising stock markets and falling unemployment. \% $\triangle R B A C R$ is the percentage change in the official cash target rate of the Reserve Bank of Australia (RBA); this measure is included since it is the main instrument of monetary policy and influences many facets of economic activity. \% the percentage change in the trade-weighted-index of the Australian dollar. Finally, the change in slope of the yield curve ${ }^{9}, \Delta 3 s 10 s$, is included since this provides information on market expectations of future economic activity and future changes in interest rates.

\section{$<$ Insert Table I >}

Table I provides summary statistics for all of the variables used within the empirical analysis. The table shows that the mean and standard deviation for both implied volatility measures was highest in the period prior to the 2007 federal election; notably this was the incumbent L-NP lost at the polls. The mean values of the measures of political uncertainty are relatively minor but exhibit a relatively large standard deviation; $\% \Delta I U_{n, t}$ was highest prior to the

\footnotetext{
${ }^{9}$ Yield curve slope is measured as the difference between the yields on 3- and 10-yr Treasury Bonds.
} 
2004 election and $\% \Delta E U_{n, t}$ highest prior to the 2010 election. Clearly, $\% \Delta I N F L$ has been the most volatile macroeconomic variable over the period considered, although it is interesting to note that this measure was generally declining whilst L-NP was the incumbent party and was increasing prior to the 2010 election when the ALP was incumbent.

Table II provides the Pearson correlation coefficients between the variables used in the regression analysis of this paper. Note the negative correlation between $\% \Delta I U_{n, t}$ and implied volatility measures, and the positive correlation between $\% \Delta E U_{n, t}$ and implied volatility measures; implied volatility declines as the incumbent becomes more likely to win since market participants have a greater understanding of the economic policies of the incumbent, while implied volatility increases as election uncertainty increases. Unsurprisingly, there is a positive relationship between the implied volatility measures for equity and bond markets. In-line with the findings of Whaley (2009) there is a significantly negative relationship between $\% \Delta A S X$ and implied volatility, that is implied volatility rises as the stock market declines and vice-versa. The correlation between the macroeconomic variables makes intuitive sense as rising (falling) interest rates (RBACR) would likely be commensurate with rising (falling) inflation, falling (rising) unemployment, rising (falling) consumer confidence, and a rising (falling) Australian Dollar.

\section{$<$ Insert Table II $>$}

\section{Empirical Results}

\subsection{Implied Volatility and Political Uncertainty}

The first stage in the empirical analysis of the role that political uncertainty plays in influencing implied volatility, and hence market uncertainty, is to perform a regression of the form:

$$
\% \Delta \sigma_{n, t}^{i}=\alpha+\beta_{1} \% \Delta I U_{n, t}+\beta_{2} \% \Delta E U_{n, t}+\beta_{3} \% \Delta \sigma_{n, t-1}^{i}+\sum_{n=1}^{k-1} \lambda_{n} \text { election fe } e_{n, t}+\varepsilon_{n, t}
$$

Where $\% \Delta \sigma_{n, t}^{i}$ is the percentage change in implied volatility of instrument $i$ (that is S\&P/ASX 200 or the 3-yr government bond), $\% \Delta I U_{n, t}$ is the percentage change in the likelihood of the incumbent party winning the election, $\% \Delta E U_{n, t}$ is the percentage change in election uncertainty, election fe $e_{n, t}$ are control variables for election fixed effects, and $\varepsilon_{n, t}$ is the error term. A one-period lagged percentage change in implied volatility is included since the volatility of the financial instruments considered is mean-reverting. 
$<$ Insert Table III >

Table III reports the results for the regression presented in Eq. (3), a disaggregation of the model into each of the election periods considered is also presented in order to allow for analysis of how the relationship has evolved over time. In consideration of the aggregate panel models, for the fixed effect specification makes it clear that the level of implied volatility decreases as the probability of the incumbent winning increases although this is only significant for equity options, providing evidence that uncertainty is lower when the prospective economic policy of election winners is known to the market; if the likelihood of the incumbent winning increases by $1 \%$ then implied volatility decreases by approximately $0.5 \%$. Election uncertainty has a significant positive effect on the implied volatility of both equity and bond option markets although the magnitude of the effect is greatest for SPX options; a 1\% increase in election uncertainty results in a $0.8 \%$ increase in SPX implied volatility and a $0.16 \%$ increase in 3-yr bond option implied volatility. Upon consideration of the disaggregated model, the influence of election uncertainty on implied volatility is apparently declining over time for both equity and bond options.

Given the historical performance of Australian financial markets in the proximity of federal elections conditional on different parties winning, it is possible that changes in implied volatility may differ dependent on the polling performance of a preferred party. A second equation is introduced:

$$
\begin{gathered}
\% \Delta \sigma_{n, t}^{i}=\alpha+\beta_{1} \% \Delta I U_{n, t}+\beta_{2} \% \Delta E U_{n, t}+\beta_{3} \% \Delta I U \cdot L N P_{n, t}+\beta_{4} \% \Delta \sigma_{n, t-1}^{i}+\sum_{n=1}^{k-1} \lambda_{n} \text { election fe } e_{n, t} \\
+\varepsilon_{n, t} \quad \text { (4) }
\end{gathered}
$$

Where $\% \Delta I U \cdot L N P_{n, t}$ is an interaction term between percentage changes incumbent uncertainty and L-NP polling performance and the other variables are defined as for Eq. (3). The results for Eq. (4) are presented in Table IV. Election uncertainty has a significant positive impact on both measures of implied volatility; that is implied volatility increases when election uncertainty rises. Additionally, the lagged implied volatility term is significantly negative in a confirmation of mean reversion. Interestingly, $\% \Delta I U$ is no longer significant, or negative, as before however the interaction term with change in L-NP polling performance is both significant and positive. This result suggests that market uncertainty is actually responding to changes in the likelihood that the L-NP Coalition will be elected rather than changes in re-election of the incumbent regardless of party affiliation. 


\subsection{The influence of macroeconomic factors}

It is possible that macroeconomic factors also have a significant influence on market uncertainty and the implied volatility of exchange traded options. Macroeconomic variables are introduced into the model specification in order to examine whether the impact of political uncertainty remains when controlling for economic conditions. A model is specified as follows:

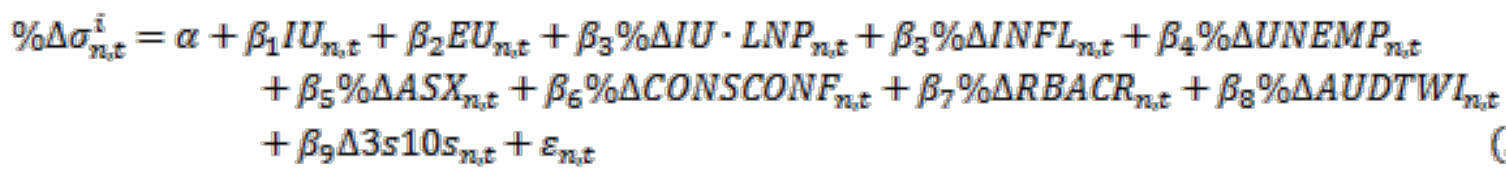

The regression results for Eq. (5) are reported in Table V. Election uncertainty appears to have a positive and significant relationship with market uncertainty, even after controlling for economic variables, although this relationship is much stronger for equity options. With Model 3, a $1 \%$ increase in election uncertainty induces a $0.58 \%$ increase in SPX option volatility, and only a $0.4 \%$ increase in bond option volatility. The likelihood of incumbents been re-elected does not have a significant relationship, but the interaction term with L-NP polling is negative and welldefined for SPX options; that is, an increase in the likelihood of a L-NP incumbent been reelected decreases stock market uncertainty.

Note the substantial increase in explanatory power, $\mathrm{R}^{2}$, as a consequence of including the macroeconomic variables. In particular, stock market returns appear to have a large impact on implied volatility. The percentage change in implied volatility of both instruments has a highly significant and negative relationship with changes in the S\&P/ASX 200 Index, i.e. implied volatility falls as the stock market rises; a $1 \%$ rise in the stock market results in a $4.07 \%$ fall in the implied volatility of SPX options and a $0.59 \%$ fall in the implied volatility of 3-yr bond options. Changes in inflation are also found to have a negative relationship with implied volatility and two related explanations exist for this: Firstly, falling inflation will decrease the probability of rate increases by the RBA and hence be positive for asset prices. Secondly, subdued inflation may evidence sound economic management by the incumbent government which will increase the possibility of re-election and hence reduce political and economic uncertainty. Given the close relationship between inflation and interest rate movements it is perhaps surprising that the coefficients for the implied volatility of bond options are not well defined. The lagged implied volatility variable remains significant and negative. 
As discussed earlier, it is likely that economic conditions will exert an influence on voting behaviour and so, in a similar vein to Goodell and Vähämaa (2013), an orthogonalization procedure is utilized to mitigate concerns related to jointly determined independent variables. Changes in election uncertainty, $\% \Delta E U$, are regressed on lagged control variables that measure changes in macroeconomic factors:

$$
\begin{aligned}
& \% \Delta E U_{n, t}=\alpha+\beta_{1} \% \Delta I N F L_{n, t-1}+\beta_{2} \% \Delta \text { UNEMP }_{n, t-1}+\beta_{3} \% \Delta \text { ASX }_{n, t-1}+\beta_{4} \% \Delta \text { CONSCONF }_{n, t-1} \\
& +\beta_{5} \% \Delta R B A C R_{n, t-1}+\beta_{6} \% \Delta A U D T W I_{n, t-1}+\beta_{7} \Delta 3 s 10 s_{n, t-1}+\varepsilon_{n, t}
\end{aligned}
$$

The residual term, $\varepsilon_{n, t}$ of Eq. (6) measures the component of $\% \Delta U E$ that is uncorrelated with the macroeconomic variables. The residuals are employed to isolate the effects of federal elections, from changes in economic conditions, on implied market volatility. \% $E U R E S I D$ is defined as the residual of Eq. (6) and is utilized in a regression specification where percentage changes in implied volatility are regressed on macroeconomic variables:

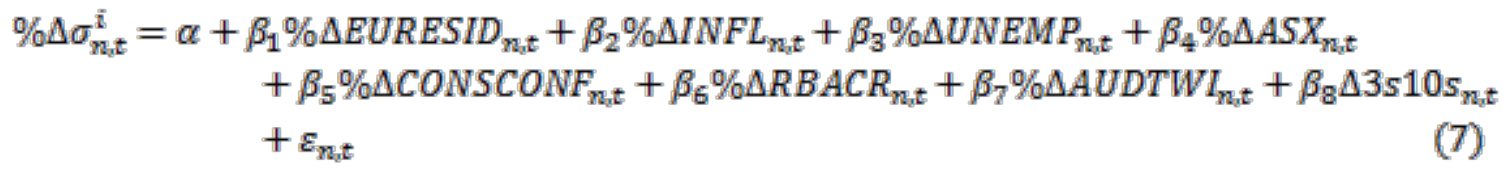

Table VI reports the estimates of the regression specified in Eq. (7). In both cases the coefficient estimates for $\% \triangle E U R E S I D$ are positive and statistically significant. These estimates demonstrate that implied volatility increases as election uncertainty increases, and also indicate that the positive association between market uncertainty and political uncertainty cannot be attributed to changes in macroeconomic conditions prompting a reaction in both election polling and implied volatility. The highly significant and negative relationship between stock market returns and implied volatility remains, as does the negative relationship between inflation and implied volatility. Finally, the mean reversion of volatility is again evident in the lagged implied volatility variable.

\section{$<$ Insert Table VI>}

In summary, consistent with $\mathrm{Li}$ and Born (2006) and Bialkowski et al. (2008), the empirical analysis provides strong evidence that election uncertainty has a significant impact on market uncertainty. In addition, the results are analogous to the more general finding of prior work such that important scheduled news events create market uncertainty which is only resolved when the outcome is known. Consistent with hypothesis $\mathrm{H}_{1}$, the election uncertainty 
measure defined here exhibits a significant and positive relationship with implied volatility. The likelihood of the incumbent remaining in power reduces implied volatility, although this is primarily driven by the interaction with the likelihood of L-NP Coalition winning the election. This is consistent with Hypothesis $\mathrm{H}_{2}$ such that the market prefers incumbents where economic policy is known, and a particular preference for the L-NP which is often viewed as more sympathetic towards business. The introduction of macroeconomic control variables greatly increases the explanatory power of the expression, and in particular there is evidence of a significant negative relationship between stock market returns and implied volatility. However, even after controlling for macroeconomic variables and the possibility that economic conditions effect voting intentions, election uncertainty remains a significant factor in determining market uncertainty in both equity and bond markets.

\section{Conclusion}

This study examines the effects of political uncertainty on implied volatility, and by implication market uncertainty, during Australian federal election cycles. Utilizing polling data from Roy Morgan Research, empirical measures of political uncertainty are constructed over five Australian election cycles between 2001 and 2013 in order to test two hypotheses.

The empirical results indicate that Australian federal election uncertainty has a significant impact on market uncertainty. In particular, the implied volatility of both equity and bond options increases in line with election uncertainty around the outcome of the poll result, while, in a case of better the devil you know, market uncertainty falls as the likelihood of the incumbent winning rises, this is especially so if the L-NP is incumbent. The results are robust to the inclusion of macroeconomic control variables, and are consistent with the notion that the Australian federal election process may result in fluctuating levels of uncertainty among market participants as they revise their expectations regarding the future direction of economic policy. The results are consistent with those reported by Goodell and Vähämaa (2013) for the U.S. Presidential election and suggest that the influence of election uncertainty is not dependent on the electoral system in place.

With polling regularity and political scrutiny increasing during the period surrounding elections, the results presented in this article provide strong evidence that market participants are likely to be effected by the level of political uncertainty. One policy implication that arises from 
the results in this paper would be that political parties may reduce uncertainty in financial markets by flagging their economic policies well in advance; of course, this would not make a difference if market participants did not believe such polices would actually be implemented or sustained in the event of an election win.

One possible area of further research would be to develop specific trading strategies that would allow market participants to benefit (or at least undertake transactions to protect capital) from changes in political uncertainty around the forthcoming federal election and future elections, particularly those investors who have exposure to volatility risk. Evidence of interest in implied volatility trading and investment profitability may also lead to the Australian Securities Exchange instituting a tradeable contract similar to that found in Chicago (CBOE). Another area of work in this fascinating area would be to utilize information from betting markets, for instance Rhode and Stumpf (2004) report that such markets did a remarkable job in an era prior to scientific polling and still offer several advantages in terms of aggregating information, and betting markets formed the basis of Goodell and Vähämaa (2013); however, betmatrix ${ }^{10}$ publish an hourly election market that may be utilised to understand the dynamics of election and market uncertainty at a higher frequency. Finally, it would be of interest to study the impact of political uncertainty on specific stocks which may be more impacted by the election outcome; for instance, Australian mining companies may be subject to differing taxation regimes dependent on the polling result.

\section{References}

Bialkowski, J., K. Gottschalk, T.P. Wisniewski, 2008, Stock market volatility around national elections, Journal of Banking and Finance, 32, 1941-1953

Chen, E.T., and A. Clements, 2007, S\&P 500 implied volatility and monetary policy announcements, Finance Research Letters, 4, 227-232

Donders, M.W.M, and T.C.F. Vorst, 1996, The impact of firm specific news on implied volatilities, Journal of Banking and Finance, 20, 1447-1461

French, K.R., and J.M. Porteba, 1991, Investor diversification and international equity markets, American Economic Review, 81, 222-26

\footnotetext{
${ }^{10}$ www.betmatrix.com
} 
Ederington, L.H. and J.H. Lee, 1996, The creation and resolution of market uncertainty: The impact of information releases on implied volatility, Journal of Financial and Quantitative Analysis, 31, 513-539

Frijns, B., C. Tallau, A. Tourani-Rad, 2010, The information content of implied volatility: Evidence from Australia, Journal of Futures Markets, 2010, 30, 134-155

Gemmill, G., 1992, Political risk and market efficiency: Tests based in British stock and options markets in the 1987 election, Journal of Banking and Finance, 16, 211-231

Goodell, J.W., and S. Vähämaa, 2013, US presidential elections and implied volatility: The role of political uncertainty, Journal of Banking and Finance, 27, 1108-1117

Hibbs, D., 1986, Political parties and macroeconomic policies and outcomes in the United States, American Economic Review, 66-70

Julio, B., and Y. Yook, 2012, Political uncertainty and corporate investment cycles, Journal of Finance, 67, 45-83

Li, J., J.A. Born, 2006, Presidential election uncertainty and common stock returns in the United States, Journal of Financial Research, 29, 609-622

Nikkinen, J., and P. Sahlström, 2004, Impact of the Federal Open Market Committee's meetings and scheduled macroeconomic news on stock market uncertainty, International Review of Financial Analysis, 13, 1-12

Pantzalis, C., D.A. Strangeland, and H.J. Turtle, 2000, Political elections and the resolution of uncertainty: the international evidence, Journal of Banking and Finance, 24, 1575-1604

Rhode, P.W., and K.S. Strumpf, 2004, Historical Presidential betting markets, Journal of Economic Perspectives, 18, 127-142

Smales, L.A., 2013, Impact of macroeconomic announcements on interest rate futures: Highfrequency evidence from Australia, Journal of Financial Research, forthcoming

Vähämaa, S., S. Watzka, and J. Äijö, 2005, What moves option-implied bond market expectations, Journal of Futures Markets, 25, 817-843

Vähämaa, S., and J. Äijö, 2011, The Fed's policy decisions and implied volatility, Journal of Futures Markets, 31, 995-1009 
Figure 1

Panel A: Polling results - 2 party preferred polling for Australian federal election

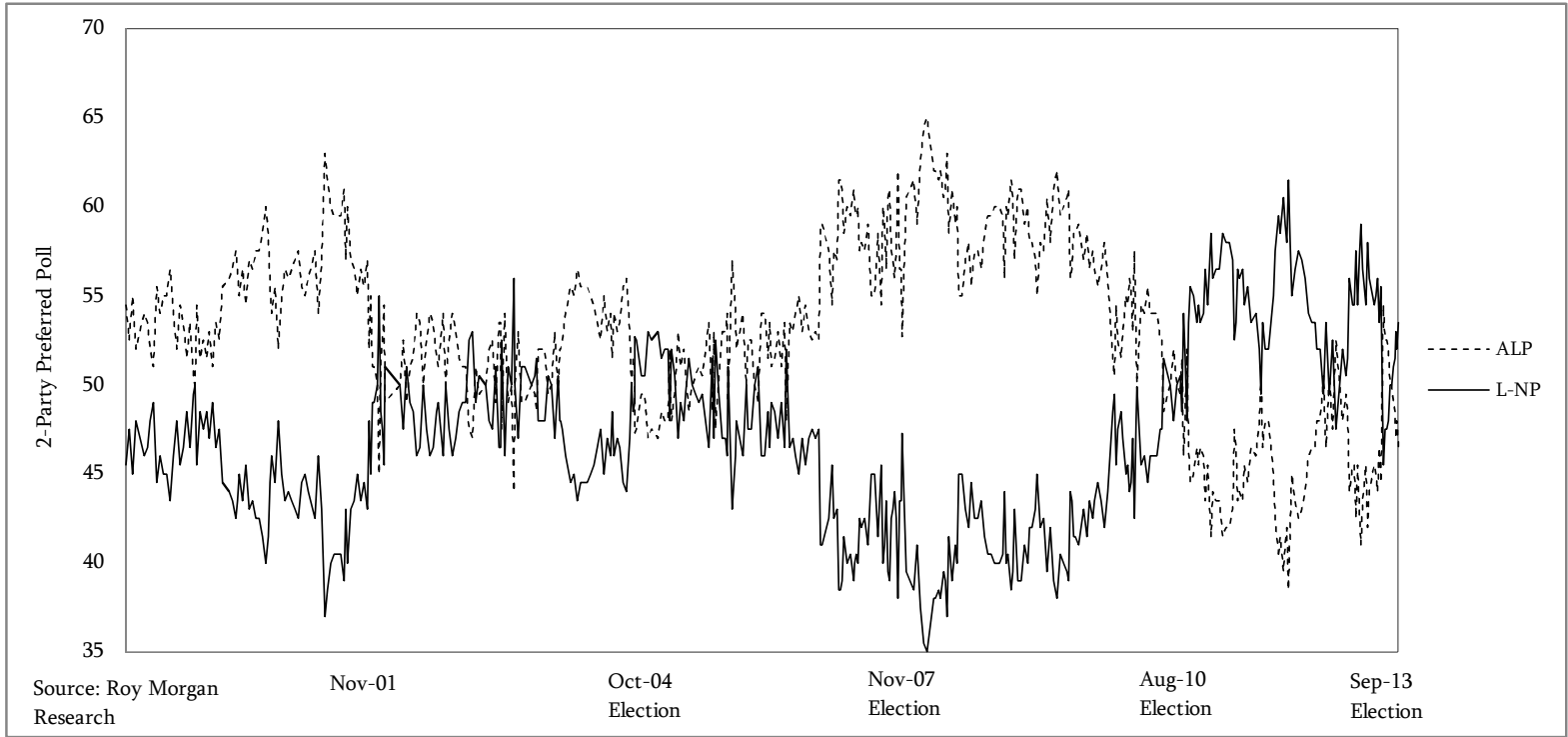

Panel B: (Re-based) Implied volatility of Australian equity and bond markets

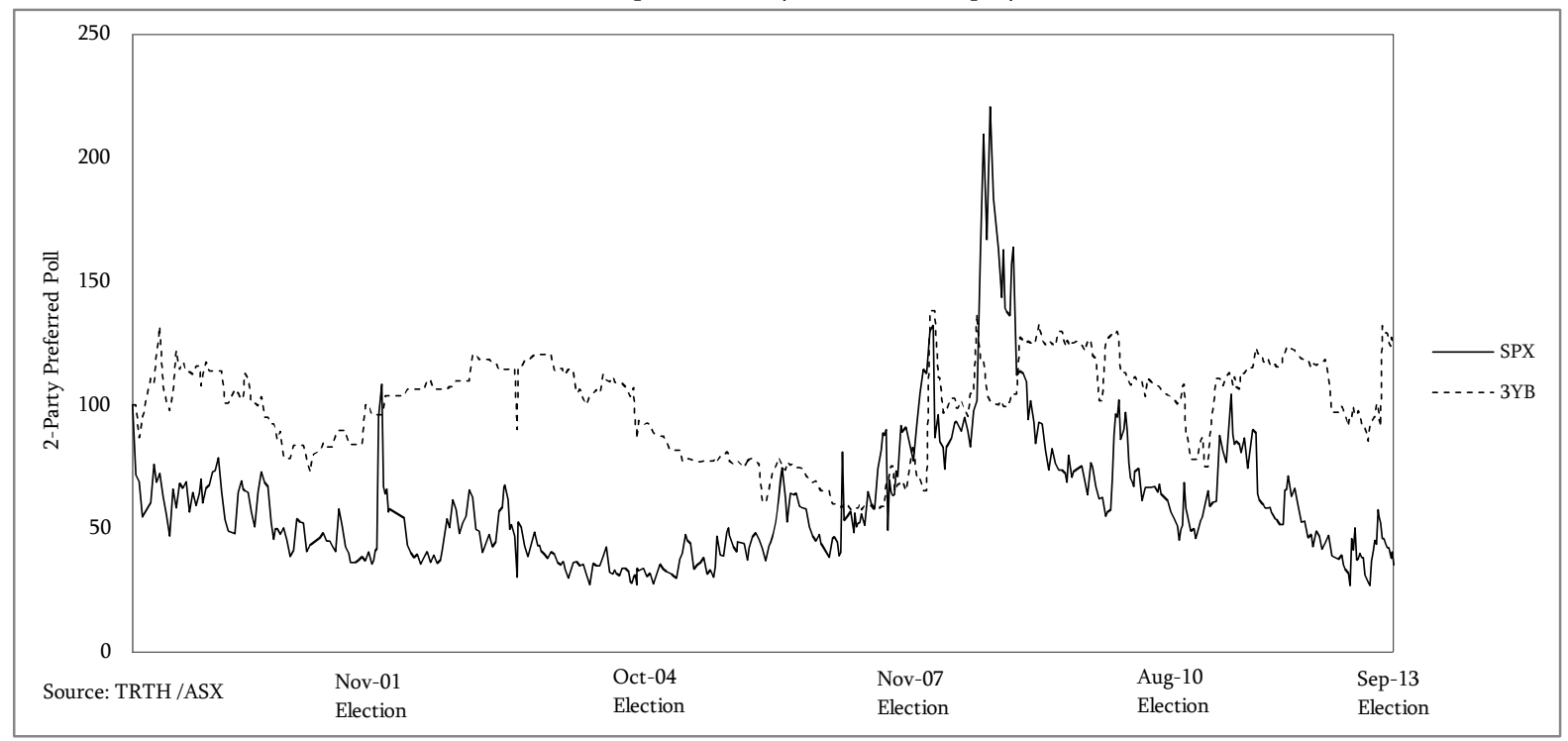


TABLE I

Summary Statistics for implied volatility, political and macroeconomic variables

\begin{tabular}{|c|c|c|c|c|c|c|c|c|c|c|c|c|}
\hline & \multicolumn{2}{|c|}{2001 Election } & \multicolumn{2}{|c|}{2004 Election } & \multicolumn{2}{|c|}{2007 Election } & \multicolumn{2}{|c|}{2010 Election } & \multicolumn{2}{|c|}{2013 Election } & \multicolumn{2}{|c|}{ Overall } \\
\hline & Mean & Std Dev & Mean & Std Dev & Mean & Std Dev & Mean & Std Dev & Mean & Std Dev & Mean & Std Dev \\
\hline$\% \Delta \sigma_{\mathrm{SPX}}$ & 0.10 & 22.97 & -0.44 & 11.43 & 2.13 & 12.67 & -0.30 & 12.11 & -2.06 & 16.10 & -0.16 & 13.23 \\
\hline$\% \Delta \sigma_{3 Y B}$ & 1.07 & 4.14 & -0.59 & 8.97 & 1.37 & 9.41 & -0.97 & 5.20 & 0.22 & 8.00 & 0.10 & 7.56 \\
\hline$\% \Delta \mathrm{IU}$ & 0.21 & 7.90 & 0.28 & 3.85 & 0.02 & 7.25 & -0.17 & 4.87 & 0.32 & 8.79 & 0.08 & 6.06 \\
\hline$\% \Delta \mathrm{EU}$ & 0.41 & 5.84 & -0.03 & 3.34 & 0.02 & 7.25 & 0.44 & 6.50 & -0.22 & 4.10 & 0.21 & 5.84 \\
\hline$\% \Delta I N F L$ & 0.27 & 1.53 & -0.07 & 0.38 & -0.44 & 0.26 & 0.16 & 0.75 & 0.14 & 0.38 & -0.02 & 0.73 \\
\hline$\% \Delta \mathrm{UNEMP}$ & 0.36 & 2.12 & -0.69 & 2.69 & -0.78 & 2.22 & -0.98 & 1.92 & 0.55 & 2.43 & -0.52 & 2.24 \\
\hline$\% \triangle \mathrm{ASX}$ & 0.18 & 2.81 & 0.43 & 1.36 & 0.60 & 2.20 & 0.28 & 3.20 & 0.58 & 2.23 & 0.37 & 2.39 \\
\hline$\% \triangle \mathrm{CONSCONF}$ & -0.75 & 6.08 & 0.14 & 2.63 & -0.38 & 5.37 & 1.32 & 5.60 & -0.19 & 4.43 & 0.08 & 4.92 \\
\hline$\% \triangle \mathrm{RBACR}$ & -1.27 & 2.37 & 0.32 & 1.40 & 0.40 & 1.19 & 1.31 & 3.32 & -1.01 & 2.26 & 0.19 & 2.07 \\
\hline$\% \Delta$ AUDTWI & 0.18 & 2.19 & 0.22 & 1.63 & 0.24 & 1.87 & 0.22 & 1.92 & -0.33 & 1.58 & 0.22 & 1.90 \\
\hline$\Delta 3 \mathrm{~s} 10 \mathrm{~s}$ & 0.04 & 0.19 & -0.17 & 0.12 & -0.03 & 0.16 & -0.07 & 0.19 & 0.06 & 0.20 & -0.06 & 0.16 \\
\hline Number of obs. & \multicolumn{2}{|c|}{29} & \multicolumn{2}{|c|}{32} & \multicolumn{2}{|c|}{31} & \multicolumn{2}{|c|}{32} & 0.33 & 1.65 & \multicolumn{2}{|c|}{124} \\
\hline
\end{tabular}

Note: This table presents summary statistics for the data used in the empirical analysis of this paper. Variables include the percentage change of implied volatility of SPX equity options and 3-yr government bond options. In addition, the percentage change in measures of political uncertainty (IU and EU) and a range of macroeconomic control variables including inflation, unemployment, consumer confidence, the RBA cash rate, and the AUD trade-weighted index are included. 
TABLE II

Correlations for implied volatility, political and macroeconomic variables

\begin{tabular}{|c|c|c|c|c|c|c|c|c|c|c|}
\hline & $\% \Delta \sigma_{\mathrm{SPX}}$ & $\% \Delta \sigma_{3 \mathrm{YB}}$ & $\% \Delta \mathrm{IU}$ & $\% \Delta \mathrm{EU}$ & $\% \Delta \mathrm{INFL}$ & $\% \Delta \mathrm{UNEMP}$ & $\% \Delta \mathrm{ASX}$ & $\% \triangle \mathrm{RBACR}$ & $\% \triangle \mathrm{CONSCONF}$ & $\% \Delta$ AUDTWI \\
\hline$\% \Delta \sigma_{3 \text { Үв }}$ & 0.273 & & & & & & & & & \\
\hline$\% \Delta \mathrm{IU}$ & -0.134 & -0.073 & & & & & & & & \\
\hline$\% \Delta \mathrm{EU}$ & 0.240 & 0.030 & 0.207 & & & & & & & \\
\hline$\% \Delta \mathrm{INFL}$ & -0.091 & -0.101 & 0.081 & 0.028 & & & & & & \\
\hline$\% \triangle \mathrm{UNEMP}$ & 0.034 & -0.122 & -0.067 & -0.001 & -0.136 & & & & & \\
\hline$\% \Delta \mathrm{ASX}$ & -0.779 & -0.222 & 0.145 & -0.252 & -0.045 & -0.027 & & & & \\
\hline$\% \triangle \mathrm{RBACR}$ & 0.123 & -0.028 & -0.079 & -0.020 & 0.376 & -0.103 & -0.129 & & & \\
\hline$\% \Delta \mathrm{CONSCONF}$ & 0.077 & -0.011 & 0.083 & 0.083 & 0.160 & -0.165 & 0.129 & 0.146 & & \\
\hline$\% \Delta$ AUDTWI & 0.168 & 0.024 & 0.008 & 0.082 & 0.145 & -0.042 & -0.114 & 0.022 & 0.302 & \\
\hline$\Delta 3 \mathrm{~s} 10 \mathrm{~s}$ & 0.320 & 0.033 & -0.202 & 0.207 & -0.093 & -0.007 & -0.291 & 0.092 & -0.150 & -0.042 \\
\hline
\end{tabular}

Note: This table reports the cross-correlations for the variables included within the empirical anaysis of this paper. Variables include the percentage change of implied volatility of SPX equity options and 3-yr government bond options. In addition, the percentage change in measures of political uncertainty (IU and EU) and a range of macroeconomic control variables including inflation, unemployment, consumer confidence, the RBA cash rate, and the AUD trade-weighted index are included. 
TABLE III

Base regression: Influence of political uncertainty on market uncertainty

\begin{tabular}{|c|c|c|c|c|c|c|c|c|c|c|c|c|}
\hline \multirow[b]{2}{*}{ Variable } & \multicolumn{6}{|c|}{$\% \Delta \sigma_{S P X}$} & \multicolumn{6}{|c|}{$\% \Delta \sigma_{3 \curlyvee B}$} \\
\hline & 2001 & 2004 & 2007 & 2010 & 2013 & Model 1 & 2001 & 2004 & 2007 & 2010 & 2013 & Model 1 \\
\hline \multirow[t]{2}{*}{ Constant } & 0.127 & -1.140 & 1.737 & -0.575 & -2.091 & 0.246 & 0.389 & -0.568 & 1.387 & -0.948 & 0.347 & 0.054 \\
\hline & $(3.722)$ & (1.487) & $(2.142)$ & (2.321) & (2.749) & (1.336) & $(0.486)$ & (1.301) & (1.507) & $(0.979)$ & (1.383) & $(0.611)$ \\
\hline \multirow[t]{2}{*}{$\% \Delta I U$} & $-1.220^{* *}$ & $-1.808^{*}$ & -0.248 & -0.047 & -0.041 & $-0.528^{* *}$ & -0.045 & -0.003 & -0.010 & -0.319 & -0.312 & -0.131 \\
\hline & $(0.586)$ & $(1.032)$ & $(0.332)$ & $(1.731)$ & $(0.544)$ & $(0.241)$ & $(0.074)$ & $(0.847)$ & $(0.257)$ & $(0.750)$ & $(0.268)$ & $(0.130)$ \\
\hline \multirow[t]{2}{*}{$\% \Delta E U$} & $2.122^{* *}$ & $1.102^{* *}$ & $0.252^{*}$ & $0.602^{* *}$ & $1.533^{* *}$ & $0.832^{* * *}$ & $0.715^{* * *}$ & $0.445^{* *}$ & $0.322^{* *}$ & $0.186^{*}$ & $0.564^{*}$ & $0.158^{* *}$ \\
\hline & $(0.830)$ & $(0.502)$ & $(0.148)$ & $(0.242)$ & (0.709) & $(0.255)$ & $(0.140)$ & $(0.197)$ & $(0.156)$ & $(0.106)$ & $(0.308)$ & $(0.074)$ \\
\hline \multirow[t]{2}{*}{$A R(1)$} & $-0.200^{*}$ & $-0.299^{*}$ & $-0.096^{*}$ & -0.084 & -0.188 & $-0.045^{* * *}$ & $-0.592^{* *}$ & $-0.229^{*}$ & $-0.182^{*}$ & 0.004 & 0.002 & $-0.227^{* *}$ \\
\hline & $(0.108)$ & $(0.173)$ & $(0.049)$ & $(0.199)$ & $(0.181)$ & $(0.010)$ & $(0.265)$ & $(0.127)$ & $(0.106)$ & $(0.179)$ & $(0.175)$ & $(0.098)$ \\
\hline Fixed or random & - & - & - & - & - & Fixed & - & - & - & - & - & Fixed \\
\hline $\operatorname{adj} . R^{2}$ & 0.293 & 0.214 & 0.209 & 0.115 & 0.138 & 0.186 & 0.740 & 0.212 & 0.132 & 0.019 & 0.082 & 0.082 \\
\hline F-Stat & 2.904 & 2.393 & 1.902 & 1.218 & 2.603 & 2.547 & 10.433 & 1.178 & 0.452 & 0.087 & 1.483 & 1.483 \\
\hline No. Obs & 29 & 32 & 31 & 32 & 32 & 156 & 26 & 32 & 31 & 32 & 32 & 153 \\
\hline
\end{tabular}

Note: This table presents results from the base regression set out in Eq. (3) whereby the percentage change in implied volatility of SPX equity options, and 3-yr bond options, are regressed on the percentage change in the two identified political uncertainty variables (Incumbent Uncertainty, IU, and Election Uncertainty, EU) as well as one-lagged term of the dependent variable. A simple linear OLS is used to disaggregate into individual election cycles, while a panel based model (with fixed time effects) is utilized to analyze the overall effect. Standard errors reported in parentheses. ${ }^{* * *},{ }^{* *},{ }^{*}$ denote significance at the $1 \%, 5 \%$, and $10 \%$ levels respectively. 


\section{TABLE IV}

Regression: Influence of political party of incumbent Prime Minister

\begin{tabular}{lcc}
\hline Variable & $\% \Delta \sigma_{S P X}$ & $\% \Delta \sigma_{3 Y B}$ \\
\hline Constant & 0.301 & 0.059 \\
& $(1.248)$ & $(0.613)$ \\
& 1.158 & 0.043 \\
$\% \Delta E U$ & $(0.756)$ & $(0.392)$ \\
& $1.496^{* * *}$ & $0.173^{* *}$ \\
$\% \Delta I U \cdot L N P$ & $(0.377)$ & $(0.087)$ \\
& $-2.216^{* *}$ & -0.226 \\
$A R(1)$ & $(0.944)$ & $(0.480)$ \\
& $-0.197^{* *}$ & $-0.227^{* *}$ \\
Fixed or random & $(0.098)$ & $(0.099)$ \\
adj. $\mathrm{R}^{2}$ & Fixed & Fixed \\
F-Stat & 0.250 & 0.085 \\
DW & 2.727 & 1.923 \\
No. Obs & 2.084 & 2.135 \\
\end{tabular}

Note: This table presents results from the regression set out in Eq. (4) whereby the percentage change in implied volatility of SPX equity options, and 3-yr bond options, are regressed on the percentage change in the three identified political uncertainty variables (Incumbent Uncertainty, IU, and Election Uncertainty, EU, and an interaction term between Incumbent Uncertainty and the incumbent Prime Minisiter been a member of the LNP Coalition) as well as one-lagged term of the dependent variable. A fixed time effects panel specification is used. Standard errors in parentheses.

${ }^{* * *},{ }^{* *},{ }^{*}$ denote significance at the $1 \%, 5 \%$, and $10 \%$ levels respectively. 
TABLE V

Regression: The influence of macroeconomic variables and political uncertainty on implied volatility

\begin{tabular}{|c|c|c|c|c|c|c|}
\hline \multirow[b]{2}{*}{ Variable } & \multicolumn{3}{|c|}{$\% \Delta \sigma_{S P X}$} & \multicolumn{3}{|c|}{$\% \Delta \sigma_{3 Y B}$} \\
\hline & Model 1 & Model 2 & Model 3 & Model 1 & Model 2 & Model 3 \\
\hline \multirow{2}{*}{ Constant } & 1.320 & 1.215 & 1.182 & 0.171 & 0.165 & 0.157 \\
\hline & $(0.826)$ & $(0.825)$ & $(0.802)$ & $(0.717)$ & $(0.718)$ & $(0.726)$ \\
\hline \multirow[t]{2}{*}{$\% \Delta I U$} & 0.184 & & $0.863^{*}$ & -0.090 & & -0.049 \\
\hline & $(0.392)$ & & $(0.487)$ & $(0.325)$ & & $(0.412)$ \\
\hline \multirow[t]{2}{*}{$\% \triangle E U$} & & $1.227^{* * *}$ & $0.575^{* *}$ & & $0.051^{* *}$ & $0.036^{* *}$ \\
\hline & & $(0.161)$ & $(0.252)$ & & $(0.022)$ & $(0.018)$ \\
\hline \multirow[t]{2}{*}{$\% \Delta I U \cdot L N P$} & $-1.132^{* * *}$ & & $-1.160^{* *}$ & 0.030 & & -0.031 \\
\hline & $(0.429)$ & & $(0.518)$ & $(0.362)$ & & $(0.522)$ \\
\hline \multirow[t]{2}{*}{$\% \triangle I N F L$} & $-0.076^{* *}$ & $-0.077^{* *}$ & $-0.067^{* *}$ & $-0.021^{*}$ & $-0.023^{*}$ & $-0.020^{*}$ \\
\hline & $(0.031)$ & $(0.031)$ & $(0.031)$ & $(0.016)$ & $(0.012)$ & $(0.011)$ \\
\hline \multirow[t]{2}{*}{$\% \triangle U N E M P$} & 0.112 & 0.124 & 0.096 & -0.108 & -0.103 & -0.110 \\
\hline & $(0.165)$ & $(0.163)$ & $(0.161)$ & $(0.137)$ & $(0.136)$ & $(0.138)$ \\
\hline \multirow[t]{2}{*}{$\% \triangle A S X$} & $-4.269^{* * *}$ & $-4.163^{* * *}$ & $-4.066^{* * *}$ & $-0.604^{* *}$ & $-0.617^{* *}$ & $-0.590^{* *}$ \\
\hline & $(0.331)$ & $(0.331)$ & $(0.336)$ & $(0.280)$ & $(0.283)$ & $(0.294)$ \\
\hline \multirow[t]{2}{*}{$\% \triangle R B A C R$} & 0.038 & 0.093 & 0.111 & 0.009 & 0.012 & 0.014 \\
\hline & $(0.329)$ & $(0.327)$ & $(0.320)$ & $(0.282)$ & $(0.282)$ & $(0.285)$ \\
\hline \multirow[t]{2}{*}{$\% \triangle C O N S C O N F$} & -0.032 & -0.045 & 0.040 & -0.007 & -0.012 & -0.003 \\
\hline & $(0.179)$ & $(0.176)$ & $(0.177)$ & $(0.148)$ & $(0.144)$ & $(0.151)$ \\
\hline \multirow[t]{2}{*}{$\% \triangle A U D T W I$} & 0.383 & 0.323 & 0.317 & -0.035 & -0.028 & -0.039 \\
\hline & $(0.326)$ & $(0.325)$ & $(0.318)$ & $(0.271)$ & $(0.270)$ & $(0.273)$ \\
\hline \multirow[t]{2}{*}{$\Delta 3 s 10 \mathrm{~s}$} & 15.637 & 13.051 & 11.953 & -2.481 & -1.906 & -2.721 \\
\hline & (11.454) & (11.253) & (11.305) & $(9.484)$ & $(9.421)$ & $(9.646)$ \\
\hline \multirow[t]{2}{*}{$A R(1)$} & -0.144 & $-0.133^{* *}$ & $-0.258^{* *}$ & $-0.222^{* *}$ & $-0.221^{* *}$ & $-0.222^{* *}$ \\
\hline & $(0.100)$ & $(0.069)$ & $(0.102)$ & $(0.105)$ & $(0.103)$ & $(0.105)$ \\
\hline Fixed/Random & Fixed & Fixed & Fixed & Fixed & Fixed & Fixed \\
\hline $\operatorname{adj} . \mathrm{R}^{2}$ & 0.668 & 0.672 & 0.684 & 0.138 & 0.135 & 0.138 \\
\hline F-Stat & 15.574 & 17.646 & 15.601 & 2.131 & 2.724 & 2.919 \\
\hline No. Obs & 148 & 148 & 148 & 138 & 138 & 138 \\
\hline
\end{tabular}

Note: This table presents results from the regression set out in Eq. (5) whereby the percentage change in implied volatility of SPX equity options, and 3-yr bond options, are regressed on the percentage change in the three identified political uncertainty variables (Incumbent Uncertainty, IU, and Election Uncertainty, EU, and an interaction term between Incumbent Uncertainty and the incumbent Prime Minister been a member of the LNP Coalition), one-lagged term of the dependent variable, and on a number of control variables for macroeconomic variables. Economic variables are the percentage change in inflation (INFL), unemployment (UNEMP), the stock market $(A S X)$, the RBA cash rate $(R B A C R)$, consumer confidence (CONSCONF), and A $\$$ trade weighted index ( $A U D T W I)$. The change in the level of the yield curve slope measure by the difference between 10-yr and 3-yr government bond yields is also included (3s10s). A fixed time effects panel specification is used. Standard errors are in parentheses. ${ }^{* * *},{ }^{* *},{ }^{*}$ denote significance at the $1 \%, 5 \%$, and $10 \%$ levels respectively. 
TABLE VI

Robustness check: Dynamic panel estimator controlling for orthogonalized deviations

\begin{tabular}{|c|c|c|c|c|}
\hline Variable & $\% \Delta \sigma_{S P X}$ & & $\% \Delta \sigma_{3 Y B}$ & \\
\hline \multirow[t]{2}{*}{$\% \Delta I U$} & 0.073 & & 0.172 & \\
\hline & $(0.373)$ & & $(0.226)$ & \\
\hline \multirow[t]{2}{*}{$\% \triangle E U$} & 0.832 & *** & 0.174 & $* * *$ \\
\hline & $(0.253)$ & & $(0.056)$ & \\
\hline \multirow[t]{2}{*}{$\% \Delta I U \cdot L N P$} & -0.659 & ** & -0.339 & ** \\
\hline & $(0.276)$ & & $(0.152)$ & \\
\hline \multirow[t]{2}{*}{$\% \triangle I N F L$} & -0.049 & & -0.017 & \\
\hline & $(0.039)$ & & $(0.025)$ & \\
\hline \multirow[t]{2}{*}{$\% \triangle U N E M P$} & 0.004 & & -0.224 & \\
\hline & $(0.216)$ & & $(0.136)$ & \\
\hline \multirow[t]{2}{*}{$\% \Delta A S X$} & -0.625 & & -0.198 & \\
\hline & $(0.454)$ & & $(0.282)$ & \\
\hline \multirow[t]{2}{*}{$\% \triangle R B A C R$} & 0.289 & & 0.381 & \\
\hline & $(0.398)$ & & $(0.252)$ & \\
\hline \multirow[t]{2}{*}{$\% \triangle C O N S C O N F$} & 0.042 & & 0.167 & \\
\hline & $(0.263)$ & & $(0.167)$ & \\
\hline \multirow[t]{2}{*}{$\% \triangle A U D T W I$} & 0.379 & & 0.137 & \\
\hline & $(0.559)$ & & $(0.360)$ & \\
\hline \multirow[t]{2}{*}{$\Delta 3 s 10 s$} & 17.162 & & 4.806 & \\
\hline & $(15.489)$ & & $(9.590)$ & \\
\hline \multirow[t]{2}{*}{$A R(1)$} & -0.237 & & -0.125 & \\
\hline & $(0.334)$ & & $(0.161)$ & \\
\hline Observations & 132 & & 132 & \\
\hline Number of instruments & 11 & & 11 & \\
\hline J-Statistic & 0.038 & & 0.126 & \\
\hline
\end{tabular}

Note: This table presents results from the dynamic panel estimator (SGMM) described in Section 3.3. Change in implied volatility of SPX equity options, and 3-yr bond options, are regressed on the percentage change in the three identified political uncertainty variables (Incumbent Uncertainty, $I U$, and Election Uncertainty, $E U$, and an interaction term between Incumbent Uncertainty and the incumbent Prime Minister been a member of the LNP Coalition), one-lagged term of the dependent variable, and on a number of control variables for macroeconomic variables. Economic variables are the percentage change in inflation (INFL), unemployment (UNEMP), the stock market $(A S X)$, the RBA cash rate $(R B A C R)$, consumer confidence (CONSCONF), and A $\$$ trade weighted index ( $A U D T W I)$. The change in the level of the yield curve slope measure by the difference between 10-yr and 3-yr government bond yields is also included $(3 s 10 s)$. Standard errors are stated in parentheses. ${ }^{* * *},{ }^{* *},{ }^{*}$ denote significance at the $1 \%, 5 \%$, and $10 \%$ levels respectively. 
Table VII

Modelling influence of political uncertainty on volatility in a GARCH(1,1) framework

\begin{tabular}{|c|c|c|c|c|}
\hline Variable & Ret_ASX & & Ret_3YBYield & \\
\hline Panel A: Conditic & & & & \\
\hline Constant & 0.134 & & 0.061 & \\
\hline & $(0.116)$ & & $(0.115)$ & \\
\hline$\% \Delta I U$ & 0.018 & & 0.007 & \\
\hline & $(0.026)$ & & $(0.020)$ & \\
\hline$\% \Delta E U$ & -0.042 & $* *$ & -0.008 & $* * *$ \\
\hline & $(0.021)$ & & $(0.002)$ & \\
\hline$\% \triangle I N F L$ & -28.695 & $*$ & 56.632 & *** \\
\hline & (15.642) & & (12.235) & \\
\hline$\% \triangle U N E M P$ & -0.062 & & 0.009 & \\
\hline & (0.039) & & $(0.037)$ & \\
\hline$\% \triangle R B A C R$ & -0.092 & $* *$ & 1.148 & *** \\
\hline & $(0.047)$ & & $(0.049)$ & \\
\hline$\% \triangle C O N S C O N F$ & 0.042 & ** & 0.025 & \\
\hline & $(0.021)$ & & $(0.019)$ & \\
\hline$\% \triangle A U D T W I$ & 0.497 & $* * *$ & 0.288 & *** \\
\hline & $(0.065)$ & & $(0.056)$ & \\
\hline $43 s 10 \mathrm{~s}$ & 1.391 & $* * *$ & 13.232 & *** \\
\hline & $(0.648)$ & & $(0.677)$ & \\
\hline Panel B: Conditio & & & & \\
\hline Constant & 2.700 & $* * *$ & 0.244 & *** \\
\hline & $(0.589)$ & & $(0.074)$ & \\
\hline$A R C H$ & 0.188 & $* *$ & 0.087 & *** \\
\hline & $(0.079)$ & & $(0.189)$ & \\
\hline GARCH & 0.410 & $* * *$ & 0.895 & *** \\
\hline & $(0.106)$ & & $(0.017)$ & \\
\hline$\% \Delta I U$ & -0.017 & ** & -0.032 & ** \\
\hline & $(0.007)$ & & $(0.013)$ & \\
\hline$\% \triangle E U$ & 0.037 & ** & 0.065 & ** \\
\hline & $(0.017)$ & & $(0.031)$ & \\
\hline$\% \triangle I N F L$ & 3.279 & & 22.926 & $* * *$ \\
\hline & (37.075) & & (7.321) & \\
\hline$\% \triangle U N E M P$ & 0.205 & ** & 0.071 & \\
\hline & $(0.095)$ & & $(0.045)$ & \\
\hline$\% \triangle R B A C R$ & 0.094 & & 0.245 & *** \\
\hline & $(0.115)$ & & $(0.064)$ & \\
\hline$\% \triangle C O N S C O N F$ & -0.158 & $* * *$ & -0.053 & $* *$ \\
\hline & $(0.051)$ & & $(0.024)$ & \\
\hline$\% \triangle A U D T W I$ & -0.592 & ** & -0.196 & ** \\
\hline & $(0.248)$ & & $(0.086)$ & \\
\hline $43 s 10 \mathrm{~s}$ & 0.821 & & -3.684 & *** \\
\hline & $(1.828)$ & & $(1.025)$ & \\
\hline adj. $R^{2}$ & 0.204 & & 0.611 & \\
\hline Log-Likelihood & -1079.7 & & -1132.7 & \\
\hline DW & 2.077 & & 2.419 & \\
\hline No. Obs & 148 & & 138 & \\
\hline
\end{tabular}

Note: This table presents results from the GARCH specification explained in Section 3.4. The dependent variables are the returns on the ASX stock index and yields on 3-year Australian government bonds. Independent variables are the percentage change in the identified political uncertainty variables (Incumbent Uncertainty, $I U$, and Election Uncertainty, $E U$ ), and on a number of control variables for macroeconomic variables. Economic variables are the percentage change in inflation (INFL), unemployment (UNEMP), the stock market $(A S X)$, the RBA cash rate (RBACR), consumer confidence (CONSCONF), and $A \$$ trade weighted index $(A U D T W I)$. The change in the level of the yield curve slope measure by the difference between 10 -yr and 3-yr government bond yields is also included $(3 \mathrm{~s} 10 \mathrm{~s})$. Standard errors are in parentheses.

***, ${ }^{* *},{ }^{*}$ denote significance at the $1 \%, 5 \%$, and $10 \%$ levels respectively. 